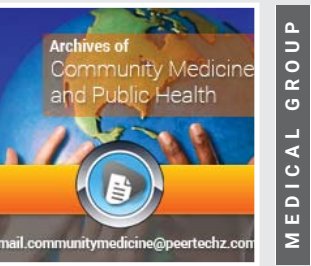

\section{Compliance with Rapid} Diagnostic Tests (RDTs) and pre-packaged Artemisininbased Combination Therapy

\section{(ACTs) guidelines among pharmaceutical outlets in Port} Harcourt, Nigeria

\author{
Ogechi Kingdom Nwankwo, Chikere Ifeanyi Casmir Ebirim* \\ and Sally NO Ibe
}

Department of Public Health, Federal University of Technology, Owerri, Nigeria
Received: 15 November, 2019

Accepted: 06 January, 2020

Published: 07 January, 2020

*Corresponding author: Chikere Ifeanyi Casmir Ebirim, Department of Public Health, Federal University of Technology, P.M.B 1526, Owerri, Nigeria, Tel: 08038870206; E-mail: chayke2000@yahoo.com

Keywords: Malaria rapid diagnostic test; Pre-packaged artemisinin-based combination therapy; Port harcourt, Nigeria

https://www.peertechz.com

Check for updates

\begin{abstract}
Background: Malaria remains the major public health problem in Nigeria which accounts for more cases of death in Nigeria than in any other country in the world. It also accounts for $60 \%$ of outpatient visits and $30 \%$ of hospitalizations among children under 5 years of age in Nigeria. The World Health Organization (WHO) recommends malaria to be tested, track prior to treatment using microscopic blood smear or Rapid Diagnostic Test (RDTs). RDTs are performed within the maximum of five minutes which allows for proper diagnosis and treatment of malaria at all level of health care. The aim of this study is to determine the level compliance with Rapid Diagnostic Tests (RDTs) and pre-packaged Artemisinin-based Combination Therapy (ACTs) guidelines among pharmaceutical outlets in Port Harcourt, Nigeria.
\end{abstract}

Methods: A cross-sectional study design was employed in this study, were 163 dispensing officers of pharmaceutical outlets were recruited through the use of simple random sampling technique of balloting. A structured questionnaire was used for data collection after being validated and its reliability tested. P-value less than 0.05 were considered statistically significant.

Results: Of the 160 participants, 80(49.1\%) were males, while 83(50.1\%) were females. Majority 154(94.5\%) of them attained tertiary education, while only $5(3.1 \%)$ attained secondary education. Hundred and sixty one (98.8\%) of the respondents have heard of RDT and are aware of what it means. Furthermore, 159(97.5\%) correctly defined RDT as an acronym for Rapid Diagnostic Test. 159(97.5\%) indicated that a positive result is characterized by Double line on the strip which reveal high compliance. Malaria rapid diagnostic testing in pharmaceutical outlets have the potentials to target antimalarial drugs more effectively. Association between Educational attainment of respondent and compliance with RDT used were statistically significant (Chi-square=7.4159. fisher's exact $=0.039$; and Chi-square=10.9651, fisher's exact=0.024 respectively).

Conclusion: Pharmaceutical outlets treat malaria but most adhere to the mRDTs and pre-packaged ACTs recommended guidelines while the rest who do not comply opined that signs and symptoms of malaria are easy to recognize hence, they prefer presumptive treatment. There's need for the government to enforce the recommended guidelines to all hence, would help to reduce over-diagnosis of malaria, over-prescription of anti-malarial drugs, drug resistance and invariably the cost of treatment especially if the testing is done appropriately. 


\section{Introduction}

Every year an appreciable number of patients die as a result of malaria due to lack of proper diagnosis and treatment. Microscopic examination of blood smear are relatively expensive, patients are often diagnose and treated symptomatically.

World Health Organization estimated that Africans, approximately one half of suspected malaria cases received parasitological confirmation and the number of courses of ACTs exceed the total number of malaria diagnostic test by factor 2, indicating that many patients receive ACTs without confirmatory diagnosis [1]. Malaria being hyper endemic in our society, individuals who exhibit one or two signs and symptoms of malaria tend to patronize drug shops especially pharmaceutical outlets due cost and proximity.

Currently, it is observed that pharmaceutical outlets evaluate diagnosis and treatment based on symptoms which is not in compliance with the WHO recommended guidelines .This has in so many ways resulted to over-diagnosis of malaria, resistance to ACTs and over- prescription of ACTs.

This situation has become alarming as good number of individuals fall victim of this method of treatment Pharmaceutical outlets are responsible for checking and dispensing of prescription drugs, providing advice on drug selections and usage to other health professional and counseling patients in proper use of drugs especially on dose and dosages. More so, as technology improves on a daily basis, pharmaceutical outlets became a place where residents visit for regular purchase of medication. Therefore, it is on this background that the research have designed this study to determine compliance with RDTs and pre-packaged ACTs guidelines among pharmaceutical outlets in Port-Harcourt, Nigeria.

\section{Materials and methods}

A cross sectional descriptive survey design was used to investigate the compliance with RDTs and pre-packaged ACTs guidelines among pharmaceutical outlets in Port-Harcourt between August 2018 to February 2019.

One hundred and sixty-three (163) dispensing officers out of 326 registered pharmaceutical outlet were randomly selected for the study using balloting.

A Semi structured self administered questionnaire containing open-ended and closed-ended questions were developed and used for data collection. The questionnaire contained relevant information on "compliance with RDTs and pre-packaged ACTs guidelines among pharmaceutical outlets in Port Harcourt, Nigeria" which was built on previously used instrument from similar surveys among pharmaceutical outlets in Nigeria. The questionnaire was divided into six major sections for ease of administration. The sections deal with the following: Social demographic data, awareness, availability, uptake, barriers and compliance with the recommended guidelines for the use of RDTs and pre-packaged ACTs among pharmaceutical outlets. Confidentiality of information was maintained throughout the study. The completed questionnaire was collated and entered into the computer. The data was analyzed using Statistical Package for Social Science (SPSS) version 21.0 computer software and the results were presented in simple percentages. Bar chart was used to present remarkable information, chi-square test used to determine associated factors to the non-usage of RDTs and ACTs. P-value less than 0.05 were considered statistically significant.

\section{Result}

\section{Socio-demographic characteristics of the respondents (Table 1)}

The table above showed the demographic characteristic of the respondents indicated that majority of the respondents $151(92.6 \%)$ were aged 20-29 years. While $12(7.4 \%)$ were aged above 30 years. Gender distribution of the respondents indicated that $80(49.1 \%)$ were males, while $83(50.1 \%)$ were females. With respect to religion $133(81.6 \%)$ were Christians, while $30(18.4 \%)$ were Islam. Documentation of the level of Education of respondents revealed that majority $154(94.5 \%)$ of them attained tertiary education, while only 5(3.1\%) attained secondary education.

Table 1: Socio-demographic characteristics of the respondents.

\begin{tabular}{|c|c|c|}
\hline Socio-demographic characteristics & Frequency $(\mathbf{n}=\mathbf{1 6 3})$ & Percentage (\%) \\
\hline Age & & \\
$20-29$ & 151 & 92.6 \\
$30-49$ & 10 & 6.2 \\
50 above & 2 & 1.2 \\
\hline Sex & & \\
male & 80 & 49.1 \\
female & 83 & 50.9 \\
Religion & & \\
Christianity & 133 & 81.6 \\
Islam & 30 & 18.4 \\
Marital status & & \\
single & 80 & 49.1 \\
married & 83 & 50.9 \\
Tribe & & \\
Igbo & 68 & 41.7 \\
Yoruba & 51 & 31.3 \\
Hausa & 12 & 7.4 \\
Others & 32 & 19.6 \\
Level of Education & & \\
primary & 2 & 1.2 \\
secondary & 5.1 \\
tertiary & 154 & 1.2 \\
non-formal education & 2 & \\
& & \\
\hline
\end{tabular}

\section{Awareness on RDTs and prepackaged ACTs recom- mended guideline (Table 2)}

Table 2 above showed the respondents awareness on RDTs and prepackaged ACTs recommended guideline. It indicated that $161(98.8 \%)$ of the respondents have heard of RDT and are aware of what it means. Furthermore, 159(97.5\%) correctly defined RDT as an acronym for Rapid Diagnostic Test. Also $159(97.5 \%)$ indicated that a positive result is characterized by Double line on the strip. 
Table 2: Information on awareness on RDTs \& Prepackaged ACTs recommended guideline.

\begin{tabular}{|c|c|c|}
\hline $\begin{array}{l}\text { Awareness on RDTs \& Pre Packaged ACTs } \\
\text { recommended guideline }\end{array}$ & $\begin{array}{l}\text { Frequency }(n= \\
163)\end{array}$ & $\begin{array}{c}\text { Percentage } \\
(\%)\end{array}$ \\
\hline \multicolumn{3}{|l|}{ Have you heard of RDT } \\
\hline Yes & 161 & 98.8 \\
\hline No & 2 & 1.2 \\
\hline \multicolumn{3}{|l|}{ Have you heard of prepackaged ACT } \\
\hline Yes & 161 & 98.8 \\
\hline No & 2 & 1.2 \\
\hline \multicolumn{3}{|l|}{ What is the meaning of RDT } \\
\hline Rapid Disease Test & 4 & 2.5 \\
\hline Rapid Diagnostic Test & 159 & 97.5 \\
\hline What is the meaning of ACT & & \\
\hline Artemisinin-based Combination Therapy & 158 & 96.9 \\
\hline Artemisinin Combination Therapy & 5 & 3.1 \\
\hline \multicolumn{3}{|l|}{ RDT positive result is characterized by } \\
\hline Single line on the strip & 4 & 2.5 \\
\hline Double line on the strip & 159 & 97.5 \\
\hline \multicolumn{3}{|l|}{ What treatment is given to RDT positive result } \\
\hline Paracetamol & 3 & 1.8 \\
\hline \multicolumn{3}{|l|}{$\begin{array}{l}\text { What treatment is given for RDT negative result } \\
\text { malaria }(A C T) \text { drug }\end{array}$} \\
\hline & 4 & 2.5 \\
\hline Flagyl & 155 & 95.1 \\
\hline Others & 2 & 1.2 \\
\hline & 2 & 1.2 \\
\hline $\begin{array}{l}\text { What are the benefits of RDT } \\
\text { RDTs are accurate }\end{array}$ & 23 & 14.1 \\
\hline \multirow{2}{*}{$\begin{array}{l}\text { RDTs are easier to use than other diagnostic method } \\
\text { RDT saves time }\end{array}$} & 7 & 43 \\
\hline & 6 & 3.7 \\
\hline All of the above & 127 & 77.9 \\
\hline \multicolumn{3}{|l|}{ What are the benefits of ACT } \\
\hline ACT efficacy high & 139 & 85.3 \\
\hline ACT efficacy moderate & 22 & 13.5 \\
\hline Others & 2 & 1.2 \\
\hline
\end{tabular}

The result also revealed that $160(98.2 \%)$ of the respondent gave malaria ACT drug once the result of RDT is positive. Also $139(85.3 \%)$ said that one of the benefits of ACT is that of its high efficacy in the treatment of malaria. One hundred and twenty seven $(77.9 \%)$ reported that the benefits of RDTs included giving accurate result, ease of use than other diagnostic methods, it also saves time. This result was similar to that reported by [2], who revealed that the respondents were confident in the results (95.4\%) from RDTs, that RDTs would reduce the unnecessary use of ACT $(87.2 \%)$ and that it gave them more confidence than microscopy results. But this was not in consonance with the work of Colombe et al., where it was reported that many respondents found malaria RDTs of no use. This can also be linked to poor awareness of mRDTs.

Figure 1 below; revealed the source of information on RDT, it indicated that majority $98(60.1 \%)$ of the respondents gained their knowledge from trainings organized by the Government. Twenty five $(15.3 \%)$ reported that their source of knowledge was through journals, 16 (9.8\%) reported that their source of information on RDT is through conferences that they attended (Figure 1, Table 3).

\section{Availability of the recommended RDTs and pre-pac- kaged ACTs}

Information on Availability of the RDTs and ACTs is shown on Table 3 above. It revealed that 155 (95.1\%) of the respondents reported that RDTs are available at their pharmacy. Out of the 163 respondents $120(73.6 \%)$ said they get their supply of RDTs through government, while 6(3.7\%) said through NGOs and $37(22.7 \%)$ said through other means. Contrary result was indicated by the report of Olugbenga, et al., [2], who indicated irregular supply of RDT kit in facilities as most of the respondents complained of stock out for the RDTs. However a study by Awoleye and Thorn [3], explained that only availability of RDTs is not enough to sustain adherence to compliance with the WHO recommendation, that it should be combined with effective communication.

In furtherance to that $120(73.6 \%)$ reported that they get their ACT drug from government agencies, 2(1.2\%) from NGOs

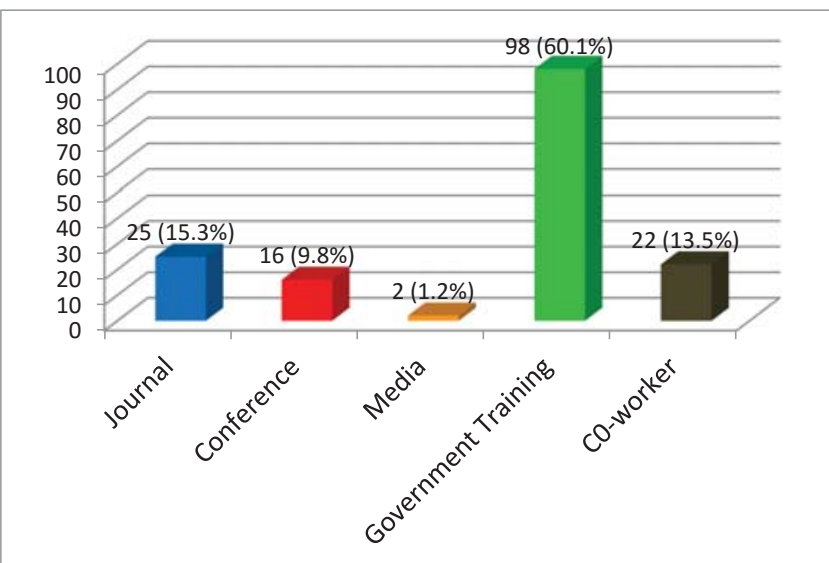

Figure 1: Source of information on RDT among the respondents.

Table 3: Availability of the recommended RDTs and pre-packaged ACTs among the respondent.

\begin{tabular}{|c|c|c|}
\hline $\begin{array}{l}\text { Availability of the recommended RDTs and } \\
\qquad \text { ACTs }\end{array}$ & $\begin{array}{l}\text { Frequency }(n= \\
163)\end{array}$ & Percentage (\%) \\
\hline $\begin{array}{c}\text { Do you have RDTs for your pharmacy } \\
\text { Yes } \\
\text { No }\end{array}$ & $\begin{array}{c}155 \\
8\end{array}$ & $\begin{array}{c}95.1 \\
4.9\end{array}$ \\
\hline $\begin{array}{l}\text { If yes, how do you get RDTS for your } \\
\text { pharmacy } \\
\text { Government } \\
\text { NGO } \\
\text { Others }\end{array}$ & $\begin{array}{c}120 \\
6 \\
37\end{array}$ & $\begin{array}{l}73.6 \\
3.7 \\
22.7\end{array}$ \\
\hline $\begin{array}{c}\text { Do you have ACTS for your pharmacy } \\
\text { Yes } \\
\text { No }\end{array}$ & 163 & 100.0 \\
\hline $\begin{array}{l}\text { If yes, how do you get ACTs for your } \\
\text { pharmacy } \\
\text { Government } \\
\text { NGO } \\
\text { Others }\end{array}$ & $\begin{array}{c}120 \\
2 \\
41\end{array}$ & $\begin{array}{c}73.6 \\
1.2 \\
25.2\end{array}$ \\
\hline $\begin{array}{c}\text { What is the ease of RDT procurement } \\
\text { Easy } \\
\text { Difficult }\end{array}$ & 163 & 100.0 \\
\hline $\begin{array}{c}\text { What is the ease of ACT procurement } \\
\text { Easy } \\
\text { Difficult }\end{array}$ & 163 & 100.0 \\
\hline
\end{tabular}

Citation: Nwankwo OK, Ebirim CIC, Ibe SNO (2020) Compliance with Rapid Diagnostic Tests (RDTs) and pre-packaged Artemisinin-based Combination Therapy (ACTs) guidelines among pharmaceutical outlets in Port Harcourt, Nigeria. Arch Community Med Public Health 6(1): 001-005. DOI: https://dx.doi.org/10.17352/2455-5479.000061 
while $41(25.2 \%)$ reported other sources. All the participants reported that RDTs and ACTs are easy to procure.

The result also showed that 151(92.6\%) complied with dispensing ACT according to recommended dose and dosages. This is as shown in Figure 2 below.

Perception of cost of RDTs revealed that $112(68.7)$ reported that the RDTs are cheap to purchase, while $21(12.9 \%)$ said it's expensive (Figure 3).

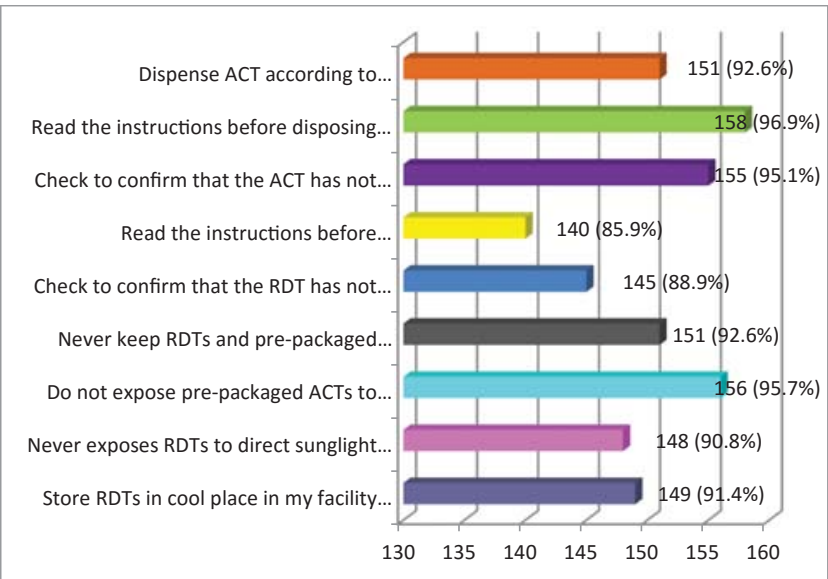

Figure 2: Compliance with recommended guidelines for RDTs and pre-packaged ACTs use among the respondents.

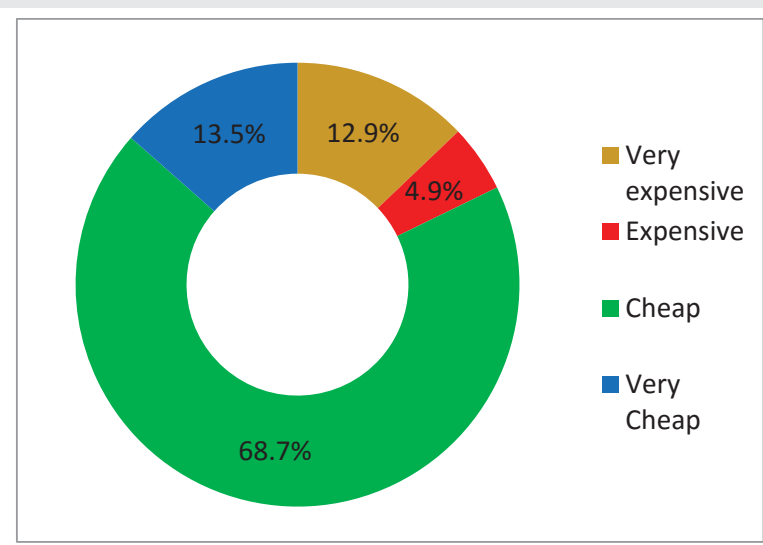

Figure 3: Doughnut chart showing Perception on the cost of RDTs and pre-packaged ACTs among the respondents.

\section{Association between educational attainments of res- pondent and compliance with recommended RDTs and ACTs among pharmaceutical outlets in port harcourt}

Test of statistical significance for the association between educational attainment of the respondents and compliance with recommended RDTs and ACTs among pharmaceutical outlets in Port Harcourt is documented below. The result indicated that those with tertiary education had 87.7percent compliance rate followed by those who attained secondary education (60.0\%), the least was found amongst those with primary (50.0\%) and no formal education (50.0\%). This was found to be statistically significant (Chi-square $=7.4159$. fisher's exact $=0.039$ ) with those who attained tertiary having complied most. In a study by Adiel, et al., there result similarly showed that readiness to accept mRDTs was significantly higher among caregivers with formal education compared to those without formal education. Implication of this finding could be said to be as a result of the fact that tertiary education exposes respondents to a wider range of information concerning health issues and awareness. This was also reported in a study by NPC,NMCP, and ICF International were it was indicated that the higher the level of education, the greater the acceptability to health care products such RDTs and Long-Lasting Insecticidal Nets (LLINS) [4-6].

\section{Conclusion}

Pharmaceutical outlets treat malaria but most adhere to the mRDTs and pre-packaged ACTs recommended guidelines while the rest who do not comply opined that signs and symptoms of malaria are easy to recognize hence, they prefer presumptive treatment. This has in so many ways resulted to over-diagnosis of malaria, resistance to ACTs and over- prescription ACTs.

It is unsurprising that despite some understanding about the usefulness of mRDT and the need for parasite-based confirmation of malaria before treatment, some caregivers are still of the opinion that presumptive diagnosis is still better.

The result indicated that most of the facilities have access to RDTs and are knowledgeable on its administration.

\section{Recommendations}

Based on the findings of this study it is recommended

1. There is need to encourage those who complied with mRDTs and pre-packaged ACTs guidelines.

2. There is a need for massive health education to those who do not comply on the importance of mRDTs and use of pre-packaged ACTs guidelines.

3. As long as pharmaceutical outlets are allowed to advice and dispense drugs to patients who come to them for treatment, they should be made to comply to this important WHO guidelines for appropriate management of patients.

4. There is need therefore, to enforce this recommended guidelines to all.

\section{Author's contributions}

Nwankwo OK. conceived the study, designed the questionnaire and performed data collection.

Ebirim CIC performed the statistical analysis, and also contributed in drafting of the manuscript.

Ibe SNO participated in review of related literature and critical review of the manuscript.

\section{References}

1. World Health Organisation (2012) Severe malaria. Tropical Medicine \&Inter national Health 19: 7. 
2. Mokuolu OA, Ajumobi OO, Ntadom GN, Adedoyin OT, Roberts AA, et al. (2018) Provider and patient perception of malaria rapid diagnostic test use in Nigeria: a cross sectional evaluation. Malar J 17: 200. Link: http://bit.ly/35vb6mz

3. Olatunji AJ, Chris T (2016) Improving access to malaria rapid diagnostic test in Niger State, Nigeria: An assessment of Implimentation up to 2013. Malar Res Treat 13. Link: http://bit.ly/39K54BJ

4. Elmardi KA, Malik EM, Abdelgadir T, Ali SH, Elsyed AH, et al. (2009) Feasibility and acceptability of home-based management of malaria strategy adapted to Sudan's conditions using artemisinin-based combination therapy and rapid diagnostic test. Malar J 8: 39. Link: http://bit.ly/37G69ss
5. Kyabayinze DJ, Asiimwe C, Nakanjako D, Nabakooza J, Bajabaite M, et al. (2012) Programme level implementation of malaria rapid diagnostic tests (RDTs) use: outcomes and cost of training health workers at lower level health care facilities in Uganda. BMC Public Health 12: 291. Link: http://bit.ly/2QOwRZ4

6. World Health Organization (2015) WHO Global Malaria Programme. World Malaria Report Geneva. Link: http://bit.ly/2T5VL98

\section{Discover a bigger Impact and Visibility of your article publication with} Peertechz Publications

\section{Highlights}

* Signatory publisher of ORCID

* Signatory Publisher of DORA (San Francisco Declaration on Research Assessment)

* Articles archived in worlds' renowned service providers such as Portico, CNKI, AGRIS, TDNet, Base (Bielefeld University Library), CrossRef, Scilit, J-Gate etc

* Journals indexed in ICMJE, SHERPA/ROMEO, Google Scholar etc.

* OAI-PMH (Open Archives Initiative Protocol for Metadata Harvesting)

* Dedicated Editorial Board for every journal

- Accurate and rapid peer-review process

* Increased citations of published articles through promotions

* Reduced timeline for article publication

Submit your articles and experience a new surge in publication services (https://www.peertechz.com/submission).

Peertechz journals wishes everlasting success in your every endeavours.

Copyright: @ 2020 Nwankwo OK, et al. This is an open-access article distributed under the terms of the Creative Commons Attribution License, which permits unrestricted use, distribution, and reproduction in any medium, provided the original author and source are credited.

Citation: Nwankwo OK, Ebirim CIC, Ibe SNO (2020) Compliance with Rapid Diagnostic Tests (RDTs) and pre-packaged Artemisinin-based Combination Therapy (ACTs) guidelines among pharmaceutical outlets in Port Harcourt, Nigeria. Arch Community Med Public Health 6(1): 001-005. D0I: https://dx.doi.org/10.17352/2455-5479.000061 